\title{
Modo mata moda. Arte, cuerpo y (micro)política en los 80
}

Lucena y Gisela Laboureau (compiladoras). Edulp. La Plata, 2016, 290 páginas. ISBN: 978-987-1985-83-8.

Modo mata moda. Arte, cuerpo y (micro)política en los 80 compilado por las sociólogas Daniela Lucena y Gisela Laboureau, y publicado por la Editorial de la Universidad de La Plata (Edulp), es un libro que nos pone en contacto con una multitud que revive a través de los recuerdos de las y los entrevistadas/os, y que permite conectar las experiencias de respuesta y resistencia al terror de la dictadura que gobernó entre 1976 y 1983 en la Argentina, y al silencio y represión que continuaron con el retorno de la democracia. Personas, lugares, alegrías y modos (más que moda, como el mismo título sugiere) se reúnen en los recuerdos y en los olvidos de los entrevistados y protagonistas de una Buenos Aires en los 80, descubriendo escenarios nuevos como el under, mientras todo afuera quedaba silenciado en vestimentas homologadas al gris-azul -como evidencia Katja Alemann (p. 77) en la entrevista-, enjaulados en la moda de los dictámenes militares, de los cuerpos disciplinados en conductas y apariencias dictadas para los jóvenes. El hilo que sigue el libro es, de hecho, una articulación entre la exigencia de la memoria y de la amnesia, como dice Manuel Hermelo a las entrevistadoras. Es decir, la necesidad de no olvidar las atrocidades que habían pasado, pero también la necesidad de olvidar para seguir adelante: "memoria y amnesia aparecían [...] evocando recuerdos dolorosos, pero era indispensable interrogar esos otros recuerdos que habían quedado en algún lugar" (p. 37), explican las autoras. Gentes, prácticas, públicos, lugares, las noches porteñas de los 80 viven, respiran y hablan en las páginas del libro para entregarnos una voz subterránea que nos relata de una alegría necesaria durante y después del silencio del terror, una alegría restituida junto a las juventudes interrumpidas; páginas que nos relatan de como los cuerpos de ausentes volvían a tornarse presentes en la ciudad, lado a lado, en su importancia, peso y modos corporales. Se puede tocar, ver y sentir a través de una pluralidad nueva a la cual la modernidad occidental ha sido poco acostumbrada. Todo ello sin olvidar las ausencias de los cuerpos desaparecidos.

El libro condensa dos voces narradoras, una sutil -la de las autoras- que pinta el escenario (como si fuese en una performance de Cemento descrita en el texto) y teje las informaciones de los recuerdos con las conexiones entre lugares y personas, reconstruyendo la potencia de la poética y política de esa nueva escena. Mientras otra pertenece a los y las protagonistas de la escena del under porteño, repuesta en diecinueve entrevistas individuales llevadas a cabo entre 2008 y 2016. Entrevistados han sido (en el orden del libro): Indio Solari, Katja Alemann, Daniel Melero, Ángel Elizondo, Omar Viola, Gianni Mestichelli, Maria José Gabin, Martín Reyna, Ana Torrejón, Marcia Schvartz, Ilse Fusková, Tino Tinto, Fernando Noy, Damián Dreizik, 
Pichón Baldinu, Vanesa Weinberg, Manuel Hermelo, Marula Di Como y Roberto Jacoby. Entre las entrevistadoras -además de las compiladoras- encontramos Ana Longoni; Lorena Verzero (autora del Prólogo también) y Bettina Girotti; Marina Suárez; Assumpta Bassas Vila y María Laura Rosa; Irina Garbatzky y Malala González. A cada entrevista realizada corresponde un capítulo, permitiendo a las y los protagonistas de narrar las experiencias estéticas y políticas puestas en escena, los recorridos personales y los cruces con los otros artistas que componían la escena del under porteño. Los capítulos/entrevistas vienen anticipados por un prólogo de Lorena Verzero y una introducción de las compiladoras, que los ordenan y propone en un marco teórico.

Como el collage aparece en la investigación cual elemento de una "estética precaria", así en la preparación del libro documentos, fotografías, recortes de diarios, revistas, grabaciones y cassettes forman un collage entre arte y política, investigación y exposición. De hecho, el material preliminar de este trabajo ha sido parte de la exposición "Perder la forma humana. Una imagen sísmica de los años ochenta en América Latina” organizada en el Reina Sofia de Madrid en el 2012 por la Red Conceptualismo del Sur. El mundo del under porteño de los 80 propone una profunda innovación de las prácticas artísticas, así como nuevas maneras de vivir el territorio y lo político. Por tanto, las autoras se concentran sobre el campo cultural y artístico focalizándose en la alegría y en la fiesta, sin olvidar la censura y la represión.

Las autoras llegan a este objeto de investigación preguntándose "¿Cómo en los años '80 se escapaba de la angustia y el desánimo?”, pues “¿Como se seguía haciendo, pensando, viviendo, en medio del silencio, las desapariciones, las torturas?”. La trama del libro va hacia las zonas de culturas más marginales desafiando las divisiones que el debate póstumo a los Ochenta ha generado, reconstruyendo un "proyecto inconsciente" que se puede reconocer o percibir a posteriori, sostiene Jacoby (p. 283). De hecho, siguiendo lo dicho por el sociólogo y animador cultural Roberto Jacoby en la entrevista que lo ve como protagonista (pp.279289), hay un nudo presente en la memoria y en la historia que divide la época de los 80 entre arte político y arte light, como si ese fuera pura frivolidad. Un nudo que encubre espacios de libertad que contestaban la visión de una sociedad dividida entre los roles de amo y esclavo. Los y las protagonistas de hecho hablan de "estrategia de la alegría" como manera de participar y organizarse distinta, nuevos modos de hacer que ponen énfasis sobre los cuerpos, que en el terror y la represión iban desapareciendo.

Las entrevistas contenidas en el libro han sido estructuradas en modo de narrar las "otredades" que la historia muchas veces encubre, es decir, la posibilidad de existir de otras formas de sociabilidad a las que venían planteadas por un orden represivo y de una forma de sociabilidad ligada a las formas de la política institucional. Por tanto, el objetivo de Modo mata moda es investigar este arte que ha sido considerado como apolítico, frívolo y hedonista, mientras proponía nuevas formas de subjetivación que desafiaban no solo la construcción de una subjetividad atemorizada, individualista y fragmentada, sino las formas de subjetivación militante propias de los partidos de izquierda y las organizaciones de lucha armada. 
El libro descubre elementos importantes que hasta ahora han quedados sumergidos, excluyendo esta movida nocturna de su tarea política. De hecho, como señala Jacoby, se ha estudiado "la economía, los personajes, las organizaciones revolucionarias, los secuestros" (p. 284), pero no se miró a la cultura en proceso, al desarrollo del ambiente under del período. La hipótesis que las autoras proponen es que esta constelación hecha por lugares como el Café Einstein, Parakultural, Cemento, el taller La Zona, Bar Bolivia, el escenario del Centro Cultural Rojas, el Paladium, lugares de formación como la Escuela Argentina de Mimo, Pantomima y expresión corporal de Elizondo, grupos como Los Melli, Los Peinados Yoli, Las Inalámbricas, La Organización Negra, Patricios Rey y sus Redonditos de Ricota, Los Encargados, Virus, Gambas al Ajillo, Las hermanas Nervio y figuras como la de Batato, Jacoby, Noy, Viola y Chabán, componen una emancipación en el nivel microfísico de la política cotidiana como afectos alegres, escapando "a las ideas de revolución y compromiso militante de las izquierdas latinoamericanas” (p. 28), y proponiendo una nueva manera de actuar en la cotidianidad. Serán los cuerpos como centro de las prácticas sociales: no más víctimas, no más culpables, sino conectados entre ellos.

Para recorrer esta constelación under y estos flujos de modos emergentes, las autoras han optado por el método de la intrusión biográfica: las entrevistas encontraban "una fuerte implicación emocional de los entrevistados, que aceptaron la invitación a recordar y a relatar su historia, aun cuando se tratara de una reactualización íntima y dolorosa de ese pasado que reaparecía cargado de sentidos" (p. 30). Las entrevistas han permitido reconstruir y visibilizar acciones que no tenían documentaciones fotográficas, vídeo, ni texto. Es con el testimonio oral que las autoras recomponen y complejizan el escenario de esta constelación, subrayando la importancia de escuchar las narraciones para afinarlas con las intenciones de ellas. El resultado es una complicidad entre entrevistadas/os y entrevistadoras que desde el recuerdo tejen la realidad de entonces. De hecho, el recuerdo juega un papel fundamental en narrar algo que parece íntimo y personal, pero se descubre como memoria colectiva (como hacen notar en el texto a través de las palabras de Halbwachs "nunca estamos sólo cuando recordamos"), permitiendo identificar las características de esta política del éxtasis (definición del Indio Solari). Estas "guaridas underground para Dionisos" (p.64) -que trataban de evitar las parálisis del miedo y que el amor no fuese desacreditado-. Lucena y Laboureau evidencian -en el puntual capítulo de introducción a las entrevistas- una estética colaborativa, una estética de la precariedad, una contra-estética vestimentaria y, por fin, una estética festiva, las cuales reproducían otro modo de situarse y vivir en la ciudad y en ese momento histórico. Estéticas que, por un lado, protegían el estado de ánimo de la muerte y del terror-cuenta el Indio (pp. 63-65)- y, por el otro, expresaban y daban valor a la vuelta a la democracia, afirmando -narra Katja Alemann (pp. 67-79)- “Estamos en democracia y esto es posible!” (p. 74). Estas mostraban una vida fuera de la tele y de las publicidades, y un cambio en los lugares donde exhibir una nueva cultura, es decir, de las casas (utilizadas en la dictadura) a los lugares públicos y alternativos. 
La estética colaborativa pone en evidencia la escasez de recursos económicos con la cual se encontraban varios artistas, la adhesión a un cuerpo con convicciones estéticas compartidas, los temores de posibles censuras y, por tanto, la exigencia de crear una estrategia que diversificaba prácticas y poéticas, exaltando al mismo tiempo heterogeneidad y pluralidad. Como evidencia Martín Reyna (pp. 139-149), poesías, canciones, pinturas, performances hacían parte de un diálogo que un cuerpo instauraba con los demás. La colaboración permitía un abrirse culturalmente a nuevas experiencias, así como a generar una nueva producción cultural y a reforzar la emergencia y afirmación de nuevos personajes, cuenta Fernando Noy (pp. 201-211), como, por ejemplo, en la narración de la introducción en la Argentina de la obra de Marosa Di Giorgio, a través de él y la figura emergente de Batato que la populariza. De hecho, las entrevistas son ricas en referencias a grupos y personas, permitiendo delinear una cartografía hecha de cruces entre los grupos (y otras figuras importantes por la escena de los 80) ya nombrados.

La precariedad es otro elemento presente en el texto que condiciona la estética de la época. Precariedad de las vidas, así como de recursos y medios. Para Alemann la precariedad se transformó en libertad en cuanto permitía experimentar con lo que había y dar lugar a la fantasía: estilos barrocos, estética del desecho, residuos del trash, o más simplemente lo que daba el basurero. En esta dirección va la experiencia de Ana Torrejón (pp. 151-161) con sus vestidos hechos con desechos, o Batato en versión "ciruja" dando vuelta por la ciudad en búsqueda de materiales para el show, o Hermelo que se define como un antecedente de los cartoneros, pasando por el desfile del Body Art en el Paladium (cuenta Tino Tinto, pp. 189-199).

La ciudad es el espacio que permite nuevas prácticas y expresiones del cuerpo, junto al descubrimiento del desperdicio como recurso. Así como sitio donde vivir una moda (una contra-estética vestimentaria) sin perjuicio, un acto íntimo que atravesaba el cotidiano y el show, afirmando un cuerpo social reconocible culturalmente que cuestionaba los códigos hasta entonces utilizados. Es todo ello lo que hace de los 80 una "marca" como dicen Lucena y Laboureau (pp. 39-40), es decir, un período que se distingue y diferencia con los códigos hegemónicos, afirmando y haciendo emerger otros signos y valores, lejos del marketing de las marcas registradas. La moda se descubre a través de nuevos modos que venían por elementos descartados en la calle o en las tiendas. Todo confluye en la estética de la fiesta, es decir una interrupción de la rutinaria normalidad donde todos estos elementos se articulan, con el fin de acercar los cuerpos en un disfrute colectivo. El texto reivindica el valor de la fiesta como momento para superar lo ocurrido y crear, inventar un tiempo futuro, algo necesario que aún no era posible entrever, a través de un aparente caos donde se cuestionaban todas las asignaciones tradicionales que afectaban los cuerpos. La fiesta es el lugar seguro para la aceptación de nuevos paradigmas que piensan en lo que estaba por venir.

Podemos afirmar, que Modo mata moda. Arte, cuerpo y (micro)política es un texto de tener en cada biblioteca para quien estudia o está interesado en los campos del arte, cultura y 
RESEÑA

política latinoamericana, con atención particular a la escena Argentina, en cuanto nos entrega las memorias, los relatos y las prácticas sociales de un escenario que quería nacer, nació y chocó con los 90 y una censura cambiante que no quiso caer y (pero) no pudo en contra de un modo que ya se había diseminado, abriendo la vía a nuevas perspectivas culturales en la sociedad.

\author{
FABRIZIO Di BuONO \\ FLACSO ARGENTINA \\ FABREDB@GMAIL.COM
}


